\title{
O DILEMA DA MIMESIS EM ARTHUR DANTO'
}

Charliston Pablo do Nascimento²

RESUMO:Esteartigotem porobjetivo abordara críticadopensador estadunidense Arthur Danto à concepção da arte como mimesis, observando que à apreensão do tema haveremos de abordar o conceito tanto sob o aspecto histórico quanto essencialista de sua filosofia. Nesse sentido, abordaremos a mimesis sob a crítica de sua condição de narrativa mestra e, a seguir, do dilema que tal concepção faz emergir no âmbito teorético quando lhe é atribuído o caráter de natureza da arte.

PALAVRAS-CHAVE: Mimesis, Essencialismo Histórico; Narrativa Mestra; Dilema de Eurípedes.

ABSTRACT: This paper aims to approach the critic of the american thinker Arthur Danto to the conception of art as mimesis, noting that to aprehend the theme we shall study the concept under the historical and essentialist aspect of his philosophy. In this sense, we will approach the mimesis under the criticism of his master narrative condition, and after, the dilemma that such a conception brings out in the theoretical framework when is assigned to it the character of nature of art.

KEYWORDS: Mimesis; Historical Essentialism; Grand Narrative; Euripidean Dilemma. 

"Os espelhos fariam bem em refletir um pouco antes de nos devolverem as imagens."

Jean Cocteau

\section{CONSIDERAÇÕES PRELIMINARES: DO IMPERATIVO DE UMA INTERPRETAÇÃO CONJUNTIVA DO ESSENCIALISMO HISTÓRICO}

Os conceitos de "fim da arte" e "arte pós-histórica" configuram os dois aspectos mais emblemáticos ou comumente afamados da filosofia da arte do pensador estadunidense Arthur Danto. Com o primeiro conceito, Danto afirma o condicionamento da arte à história da filosofia da arte e de suas narrativas mestras - notadamente, da mimesis como história de um progresso, e da expressão como crise desse progresso - chegando ao seu fim quando, segundo o autor, ao debate das narrativas mestras apresentou-se o problema da definição do que é arte diante a eleição à condição de obra de arte de um objeto perceptualmente indiscernível a um objeto comum, exemplificada pelo autor com as Brillo Boxes, de Andy Warhol, cuja constituição se mostrava perceptualmente indiscernível a caixas de sabão da marca Brillo que poderiam ser encontradas em depósitos de supermercados. Por sua vez, com o segundo conceito, isto é, "arte pós-histórica", Danto traz ao debate filosófico da arte o juízo de que subsequente à apresentação do problema da indiscernibilidade entre objeto e obra, seguiu-se, a partir da década de 1970, uma era de radical pluralismo no mundo da arte, de sorte que as proposições artísticas, agora não mais se beneficiando de uma narrativa mestra legitimadora, tampouco poderiam validar a constatação do prosseguimento da história 
da arte compreendida como narrativa de um progresso estilístico. A referência aos conceitos de fim da arte e arte pós-histórica, acima, possuem nesse artigo um papel puramente ilustrativo de um problema, qual seja: de que embora a filosofia da arte do pensador estadunidense aborde as questões referentes ao mundo da arte sob uma perspectiva histórica, tal como se pode verificar nas proposições de um fim histórico da arte, na afirmativa da história da arte como história de narrativas mestras, ou ainda no juízo de que a arte subsequente à década de 1970 seria uma arte pós-histórica, por outro lado a avaliação de sua filosofia da arte e de seu caráter histórico podem se mostrar problemáticos se apreendidos tão só por uma perspectiva histórica, posto que sua filosofia da arte seja também essencialista.

Em Danto, deste modo, encontramos no essencialismo histórico uma dupla definição da natureza da arte, e, consecutivamente, é sob esse prisma, que à primeira vista poderia aparentar uma formulação teórica paradoxal, que uma investigação em torno de sua filosofia da arte deverá se atentar. $\mathrm{O}$ essencialismo, no pensamento do filósofo estadunidense, se apresenta enquanto caráter intensional da arte, devendo o objeto proposto como obra cumprir a duas exigências para que assim seja eleito: a) ser sobre alguma coisa, e b) incorporar o seu significado (Danto, 2010, p.215). Deste modo, o caráter intensional de sua teoria afirma que para que algo seja arte, independente da cultura ou época em que tenha sido produzido, é necessário que, em princípio, possa contemplar a essas duas exigências. Todavia, é enquanto predicado extensional que o conceito de arte se mostra histórico. Com o emprego desse caráter, o autor busca elucidar que as obras produzidas nos diferentes estágios ou culturas, 
necessariamente não precisam assemelhar-se estilisticamente umas com as outras, sem com isso estarem de encontro ao caráter essencialista ou intensional. Consequentemente, para Danto, ao se afirmar que a extensão do termo obra de arte é histórica, não se nega o caráter intensional essencialista, nem, por sua vez, que este último aspecto não fundamente o pluralismo enquanto característica extensional da arte: antes, são conjuntivos. Cito-o:

Por "essencialista", refiro-me à condição de a arte ser uma definição mediante condições necessárias e suficientes [...]. O conceito de arte, enquanto essencialista, é atemporal. Mas a extensão do termo é historicamente indexada - na verdade, como se a essência se revelasse a si mesma por meio da história, parte do que acredita-se que Wölfflin deu a entender ao dizer que 'nem tudo é possível em todos os tempos, e certos pensamentos só podem ser concebidos em certos estágios de desenvolvimento'. [...] Dado que a extensão do termo 'obra de arte' é histórica de modo que as obras nos diferentes estágios não se pareçam obviamente umas com as outras, está claro que a definição de arte tem de ser consistente com todas elas já que todas devem exemplificar a essência idêntica. [...] $\mathrm{O}$ conceito de arte tem de ser consistente com tudo o que é arte. Segue-se daí que a definição não impõe imperativos estilísticos de espécie alguma [...] o essencialismo na arte impõe o pluralismo, seja ele ou não, de fato, historicamente percebido (DANTO, 2010, p.215-218).

É diante esse duplo princípio teórico da natureza da arte exposto acima, portanto, que abordaremos, a seguir, o alicerce de nossa investigação em torno da crítica de Arthur Danto ao conceito de mimesis. Inicialmente, abarcaremos a crítica ao conceito 
no que tange ao seu caráter extensional/histórico de narrativa mestra, contextualizando-a junto à problemática da expressão como narrativa e a subsequente formulação do conceito de fim da arte e, a seguir, ilustraremos a problematização do conceito de mimesis enquanto condição necessária e suficiente para a definição intencional/essencialista do que é arte, destacando a assertiva do "dilema de Eurípedes", expressão por meio da qual o pensador estadunidense procura realizar sua crítica essencialista ao conceito.

\section{MIMESIS E EXPRESSÃO COMO NARRATIVAS MESTRAS}

A investigação de Danto acerca do problema relativo à arte em sua historicidade narrativa começa a sobressair em sua teoria a partir da publicação de seu artigo The end of art: a philosophical defense, de 1984. No artigo em questão, o pensador estadunidense questiona se não é possível que a Idade da Arte tenha se esgotado, envelhecido em sua forma de 'vida' (Danto, 1984, p.129). Tal apreensão se mostra relevante em dois aspectos: primeiramente, por conjugar ao conceito de arte um caráter historicidade, atribuindo-lhe uma existência história (isto é, uma era ou idade da arte), bem como por se valer do conceito hegeliano de fim da arte para apresentar um juízo empírico acerca da arte de nosso tempo. É justamente na construção desse argumento que o pensador procura elucubrar a evolução dos paradigmas e juízos em torno do conceito de arte e de seus valores, intitulando-os narrativas mestras, e empregando-os como alicerce para a conclusão de que o fim da legitimidade de tais narrativas incidiria o fim da arte ou de sua idade histórica.

A afirmativa de uma Era ou Idade da arte, no pensamento dantiano, incide a necessidade de diferirmos no conceito de 
arte um princípio teorético que não abarca e nem se confunde, necessariamente, com uma Era ou Idade das produções de imagens ou artefatos pelos seres humanos. Analogamente a Hans Belting, que à mesma época chegara a uma similar apreensão de um fim da arte na arte contemporânea em sua obra $O$ fim da história da arte, embora as produções artísticas possuam semelhança a outros artefatos históricos em razão de também produzirem imagens, e mesmo que após os movimentos de vanguardas tenha havido a proposição de uma releitura de artefatos primitivos a uma reconsideração estética, é tão-somente com o Renascimento, para Danto, que se pode asseverar o advento de uma era da arte. Nessa perspectiva, afirma o pensador estadunidense:

Não que aquelas imagens [anteriores ao Renascimento] deixassem de ser arte em um sentido amplo, mas serem arte não fazia parte de sua produção, uma vez que o conceito de arte não havia ainda surgido de fato na consciência geral, e essas imagens - ícones, realmente - desempenhavam na vida das pessoas um papel bem diferente daquele que as obras de arte vieram a ter quando o conceito finalmente emergiu e alguma coisa como considerações estéticas começaram a governar nossas relações com elas. Teria havido, então [no Renascimento] uma profunda descontinuidade para com as práticas artísticas anteriores da era da arte ter se iniciado, de modo a que o próprio conceito de artista se tornou central na Renascença, a ponto de Giorgio Vasari ter escrito um grande livro sobre a vida dos artistas, ao passo que antes elas sequer fossem pensadas como arte no sentido elementar de terem sido produzidas por artistas - seres humanos colocando marcas em superfícies - mas como tendo uma origem que nos é miraculosa e de finalidade votiva (2006, I, p.4). 
Dentro dessa perspectiva de uma Era das Artes, Danto assevera existirem dois modos preponderantes de narrativa histórica: o primeiro, intitulado concepção mimética da arte, funda-se como modelo progressivo da história da arte, tendo por objeto uma identificação da história estilística com a conquista gradual das aparências naturais. Neste âmbito, o progresso se realiza em função da decrescente distância entre as simulações óticas reais e pictóricas, mormente a partir de paradigmas em consonância com a evolução técnica de instrumentos óticos e da própria técnica do fazer artístico. Desta forma, afirma Danto, pode-se notar sem grandes dificuldades o quanto algumas conceituações se voltam a uma noção mais generalizada da procura por uma cópia o mais fiel da realidade (p.ex., se trilharmos a pesquisa visual para o progresso principiado por Cimabue, passando por Giotto, chegando a Ingres e Vermeer, e, por fim, nos pormenores possíveis à fotografia e à filmagem cinética), como também para com aspectos técnicos menores em que, por exemplo, dialoga-se a perspectiva e a tecnologia da representação, a representação do movimento e a imagem cinética de desenhos animados e filmes, a passagem do preto-e-branco para o colorido na evolução técnica dos meios cinematográficos, bem como, por fim, à adição de som como um meio de se chegar à mimesis da realidade. (Danto, 1984, p.133).

No que diz respeito à consideração mimética da arte, salienta o pensador estadunidense que tanto os juízos de valor como uma tentativa de previsão futura da arte se alicerçam em caracteres evolutivos em termos de progresso da representação da imagem. Afinal, afirma Danto, "ainda hoje se fala na possibilidade de mimetizar o olfato em veículos artísticos, tal como quarenta anos atrás se cogitava a possibilidade do uso de uma tecnologia 3 D". Por sua vez, e em consonância com o exposto acima, é tão- 
somente "a partir de um paradigma mimético da arte que se adota o conceito de obra-prima, no qual o juízo se fundamenta pelo virtuosismo da realização da obra" (DANTO, 1984, p.133).

Segundo Arthur Danto, está no segundo estágio de concepção da arte o afloramento da complexidade de seu debate teórico. Iniciada como reação à teoria mimética da arte, a teoria da arte como expressão se manifesta quando a evolução das tecnologias representacionais (p.ex., a fotografia e seu emprego por Muybridge para demonstrar o correto movimento de cavalos em corridas) levaram pintores e escultores a se interrogarem sobre como competir com esta inovação técnica e, a seguir, o que fariam em um pretenso futuro no qual a câmera também conseguisse alcançar o relevo (Danto, 1984, p.136). Nessa perspectiva, obras que reagiam à crescente evolução técnica, tal como a dos impressionistas em seu retorno ao campo e preocupação com a luz, conduziram a estágios mais radicais com os fauvistas e as conseguintes vanguardas, movimentos nos quais a arte já não mimetiza. Por outro lado, e tendo por base os juízos da teoria mimética da arte, as novas obras foram inicialmente recebidas com assombro e como sendo sintomáticas de uma involução artística, necessitando-se, destarte, de uma inovadora justificação teórica dos novos movimentos artísticos.

Cada vez era mais evidente que se necessitava com urgência de uma nova teoria, que não eram os artistas que estavam fracassando em seus diagnósticos perceptivos, e sim que buscavam algo absolutamente incompreensível à primeira concepção. Há de ser dito, em favor da estética, que seus representantes responderam a esta nova situação elaborando teorias, muitas vezes falidas, nas quais se reconhecia esta necessidade. Um bom exemplo 
é a pertinente afirmação de que os pintores, mais do que representar, estavam expressando algo (a estética como ciência da expressão apareceu em 1902). De acordo com isto, a mancha verde no rosto nos conduz a questionar o que Matisse sentia em respeito à sua modelo (sua própria mulher), demandando um complexo ato de interpretação por parte do espectador. De fato, o espectador deve apontar hipóteses distintas: se o objeto se mostra tal como se mostra, é porque o artista o sente tal como o sente. Se De Kooning pinta uma mulher com largas pinceladas, se El Greco pinta santos com formas verticais estiradas, se Giacometti modela figuras incoerentemente demarcadas, não é por razões óticas nem porque essas mulheres, santos e figuras sejam realmente assim, mas porque os artistas revelam respectivamente sentimentos de agressividade, apelo espiritual e compaixão (DANTO, 1984, p.137).

Segundo a crítica dantiana, a teoria da arte como expressão necessitou em princípio acomodar justificativas para o próprio intento expressivo de seus artistas. Deste modo, tornou-se comum no período inicial das vanguardas artísticas, por exemplo, a afirmação de que o apelo subjetivo do artista se manifestava como uma escolha pela expressão, e não pela falta de um elevado domínio técnico. Deste modo, não são raras as exemplificações em que para valorar as cores e traços fauvistas de Matisse, ou as formas cubistas analíticas e sintéticas de Picasso, recorria a crítica ao período antecedente de criações dos mesmos artistas, quando se valiam da teoria mimética da arte para a realização de suas obras, para se afirmar possuírem um domínio técnico virtuoso, de modo que poderiam justificar a adoção por um paradigma expressivo. 
Para Danto, a teoria da arte como expressão inaugura uma crise nos próprios juízos valorativos do mundo da arte. Se na arte mimética o caráter evolutivo da representação é passível de verificação, por outro não se pode falar em uma sequência evolutiva do conceito de expressão. Afinal, como determinar que um artista expressasse mais que outro se o próprio termo expressar inclui uma complexidade infinita de sensações possíveis? Nesta conceituação de arte, portanto, não se pode falar em virtuosismo ou qualificar seus representantes e suas obras a adjetivações como "melhor artista que..." ou "melhor obra que...", tendo-se em vista a impossibilidade de um método para determinar uma maior ou menor expressão em um artista e sua obra. Neste sentido, afirma Danto, a história da arte converte-se em uma história das sucessivas vidas dos artistas e suas inovações expressivas (que, notadamente, não se fundam em nenhum critério de avaliação).

Danto ressalta no advento e consequências críticas da teoria da arte como expressão um novo estágio na história da estética (que, por sua vez, se reflete nos acalorados e numerosos debates dentro desse campo teórico da filosofia no século XX): a passagem da representação mimética, afirmada como uma tese na qual os critérios avaliativos possuem uma fundamentação concernente aos objetos, para uma arte de expressividade manifesta (antitética à primeira) dá origem a um conflito não apenas de ordem da teoria da arte, mas, da emergência crucial de uma reflexão acerca do que consiste a natureza da arte em sua totalidade. Esta nova fase, relacionando de modo direto as obras e os conflitos teóricos acerca da natureza na qual as mesmas se inserem, cria um estágio no qual os problemas cognitivos resultantes daquelas se manifesta em um novo estágio do movimento histórico e conceitual da arte, e no qual a arte se projeta à procura de conhecer-se, 
isto é, adquirindo uma espécie de autoconsciência que faz romper a natureza tanto do caráter representacional mimético quando da expressividade, terminando por fazer com que a arte chegue ao seu fim histórico com o advento de sua própria filosofia. A arte, nesse novo estágio, deixa de ser uma espécie de manifestação para depender e se fazer como teoria. Cito-o:

Ao que parece, existe uma conexão interna entre a natureza e a história da arte. A história acaba com o advento da autoconsciência, ou melhor, do autoconhecimento. Supondo que nossas histórias pessoais - ao menos nossas histórias formativas - respondem de certo modo a essa estrutura e que acabam com o amadurecimento, entendidos como conhecimento - e aceitação - do que somos. A arte chega ao seu fim com o advento de sua própria filosofia. A importância histórica da arte reside, portanto, em fazer que a filosofia da arte seja possível e relevante. Se focarmos a arte de nosso passado recente a partir dessas conclusões, encontramo-nos com algo que depende cada vez mais de uma teoria para existir como arte; a teoria não é algo alheio ao mundo que se pretende conhecer, e sim porque para compreender seu objeto tem de compreender a si mesma. A arte tem pairado em um lume de mera autorreflexão, convertida no objeto de sua própria consciência teórica (DANTO, 1984, p.139).

O conceito de fim da arte em Danto, deste modo, diz respeito não a um período em que a confecção de obras de arte deixaria de existir, nem tampouco se funda em uma leitura histórica na qual a um período sucederia outro absolutamente distinto. Para o pensador estadunidense, não houve um período limite em que todas as obras deixaram de mimetizar em vista da expressão, mas, 
tão-somente, que a afirmação desta nova conceituação insurgente contra aquela deu origem a uma nova problemática de ordem valorativa e que, por sua vez, diz sobre os próprios critérios avaliativos nos quais o mundo da arte se alça para exercer sua narrativa histórica. Caso semelhante ocorre com a passagem desse período de crise para a questão do fim da arte. Com este conceito, o pensador norte-americano denota um que o aparecimento de obras cujo caráter é ele mesmo afirmador de um questionamento da natureza da arte demonstra uma nova ruptura que não apenas se manifesta contra os dois primeiros como, primordialmente, torna-os e a si à questão: "isto é arte?" (DANTO, 1984, p.140).

\section{A MIMESIS COMO PROJETO E O DILEMA DE EURÍPEDES}

Embora a investigação acerca da mimesis, enquanto narrativa histórica, tenha no renascentista Giorgio Vasari, ou em teóricos mais contemporâneos como Ernst Gombrich os exemplos mais empregados por Danto para o desenvolvimento de sua argumentação teórica no âmbito extensional, principalmente a partir de After the end of art: Contemporary art and the pale of history, a interrogação essencialista da natureza da arte, em sua crítica à teoria da arte como imitação, remontará um período que precede ao da própria Era da Arte: a Grécia clássica e a formulação do conceito de mimesis como natureza da arte.

No artigo O mundo da Arte, de 1964, Danto dispõe uma parcela significante do texto para o trato do que intitula Teoria Imitativa da Arte, ou TI, como alicerce para a crítica ao conceito de mimesis como condição necessária e suficiente à interrogação 'o que é arte?'. Para explanar o seu entendimento 
da concepção de arte como mimesis, o autor toma emprestada uma definição de arte como mimesis que afirma encontrar tanto em Hamlet, personagem da peça homônima de Shakespeare, quanto no filósofo grego Sócrates, a partir dos escritos de Platão. Segundo Danto, estes personagens falaram de arte como um espelho anteposto à natureza:

Sócrates [afirma Danto] vê os espelhos como que refletindo o que já podemos ver. Assim, a arte, na medida em que é como o espelho, fornece duplicações pouco acuradas das aparências das coisas e não presta qualquer benefício cognitivo. Hamlet, [de outro modo], reconheceu uma notável característica das superfícies refletoras, a saber, que elas nos mostram o que, de outro modo, não poderíamos perceber - nossa própria face e forma - e, do mesmo modo, a arte, na medida em que ela é como espelho, nos revela a nós mesmos e é de alguma utilidade cognitiva no final das contas (DANTO, 2006, p.13).

No mesmo artigo, em uma passagem posterior, Danto esclarece que essa concepção relativa à arte figurou ao longo de parcela relevante da história das produções artísticas, e que, embora não se possa reduzir todo esse período histórico a uma Teoria Imitativa da Arte, visto terem existido várias teorias ao longo de sua história, todas elas foram "mais ou menos definidas em termos de TI" (2006, p.15). Essa concepção da arte como um espelho anteposto à natureza, por conseguinte, decai em um problema de ordem conceitual, que, segundo Danto, não fora notado pelos artistas em seus empenhos de imitação até o século XIX, com a invenção da fotografia. Eis a questão que se apresenta: "se a imagem espelhada de o é mesmo uma imitação 
de o, então, se a arte é imitação, imagens espelhadas são arte”. Para Danto, assim sendo, a consideração acerca da natureza da arte encontra na Teoria Imitativa um argumento que deve ser rejeitado enquanto condição necessária para o que é arte, visto que "é imitação" não determina uma condição suficiente para "é arte" (2006, p.13). É diante dessa problemática que o autor aponta para o fato de que tal concepção acerca da arte, após o abstracionismo teorizado e praticado por Kandinsky, passou a ocupar um lugar periférico na crítica de arte.

É na obra Transfiguração do Lugar-comum, não obstante, que o filósofo estadunidense buscará aclarar, sob o preceito ansiado de construir uma ontologia da obra de arte, o problema da mimesis sem se fundamentar em fatores que se amparam tão só no processo histórico da prática artística e, ao mesmo tempo, retomando e expandindo essa primeira consideração anteriormente abordada no artigo Mundo da Arte, na qual se afirma que se a arte é uma imitação da realidade, consequentemente toda imagem espelhada deverá ser considerada, também, uma obra de arte, abordando-a como um dilema que remonta ao racionalismo da tragédia euripediana.

$\mathrm{Na}$ Transfiguração, Danto observa que a imitação, ao incidir na representação de uma realidade pré-existente, conduz ao ensejo filosófico a necessidade de se pensar o próprio conceito do que é representar, visto que tal conceito demonstra uma ambiguidade quando referido a situações díspares. Amparando-se na análise de Nietzsche acerca dos rituais dionisíacos que deram origem à tragédia, o pensador norte-americano observa que anterior à concepção da representação artística e ao distanciamento estético que ela possibilita na obra, o objeto representado existiu de modo a se identificar não com aquilo que está a reproduzir, mas, 
com uma espécie de (re)apresentação possibilitada pelo rito. À leitura de Nietzsche, segundo Danto, os rituais dionisíacos, celebrações orgiásticas em que os participantes buscavam alcançar um estado de frenesi e no qual o entorpecimento das faculdades racionais e das inibições morais tornava presente aos praticantes a presença do próprio Dioniso, (re)apresentado, conduz à apreensão de um caráter diverso entre o objeto representado e o mito (re)apresentado.

Para o pensador estadunidense, obviamente, não se pode afirmar que nos rituais dionisíacos houvesse uma aparição divina de modo literal, mas, por intermédio de alguém que o representava. Essa consideração, observa Danto, nos leva a refletir que se por um lado não se pode deixar de considerar que nos rituais dionisíacos havia alguém que representava Dioniso (fazendo, de algum modo, uma mimetização), por outro lado a identificação dessa representação com uma interpretação que lhe aufere um sentido de caráter religioso o torna algo diverso ao que era enquanto mera coisa, o que pode ser assimilado, em nossa cultura cristã, com o fato de que a água benta não é somente água, por impossível que seja distingui-la da água comum. Em uma apreensão mais abrasileirada, diríamos que a galinha usada no despacho não é a mesma empregada em uma refeição. "Acreditava-se", afirma Danto, "que Dioniso aparecia aos participantes do ritual" no sentido de uma aparição que se fazia presente naquele que representava, de modo que "se alguém achasse que era somente uma imitação, os demais diriam que o ritual havia fracassado" (2005, p.55-57). Prossegue o autor:

O 'artista' tinha o poder de tornar de novo presente uma determinada realidade em um meio completamente diferente, como um deus; para os fiéis, uma efígie da 
crucificação era como se o acontecimento se fizesse outra vez presente, por milagre... Não fosse a existência prévia desse tipo de crença, como se poderia explicar a exigência da iconoclastia ou a interdição das imagens esculpidas?... De qualquer modo, quando uma coisa deixa de ser uma (re)apresentação da crucificação e passa a ser o que eu chamaria de representação da crucificação —uma mera pintura - a congregação de fiéis já se tornou um público e não uma reunião de compartícipes numa história simbólica, e uma parte das paredes da igreja transformou-se nas paredes de uma galeria (2005, p.57).

A passagem acima demonstra que, para o filósofo estadunidense, para além de na origem da arte se encontrar uma interpretação que confluía à representação uma (re) aparição do mito, tal aspecto nos leva a considerar o caráter relevante da interpretação acerca do objeto como algo que o transfigura. Entretanto, é esse mote da leitura de Nietzsche do nascimento da arte trágica que o leva a outra consideração teorética fundamental à sua crítica ao conceito de arte como mimesis: a identificação de Eurípedes com o advento da arte como um projeto de imitação da realidade (DANTO, 2005, p.64).

Em O Nascimento da Tragédia e na conferência Sócrates e a Tragédia, Nietzsche afirma ser a obra de Eurípedes responsável pela decadência do espírito trágico nas peças trágicas, tendo em vista que sua obra realiza uma inversão da soberania da intuição pelo racionalismo na arte. Partindo de uma preocupação semelhante às de outros poetas trágicos de conduzir nas primeiras cenas da tragédia todos os elementos necessários para o entendimento da obra, Eurípedes acreditava ter percebido que ali, naquelas primeiras cenas, havia sempre uma inquietação 
por parte do público que procurava compreender e calcular a história antecedentemente (Cf. NIETZSCHE, 2005, p.79; 2000, $\S 12)$. Na concepção de Eurípedes, esse problema relativo à falta de compreensão levaria à perda de grande parte da poeticidade da peça, de modo que para aclarar o entendimento por parte do público, criou o prólogo. Ademais, segundo Nietzsche, as reflexões daquele poeta trágico o induziram a uma reforma naturalista que acabou por instaurar uma relação de dependência entre a poesia e o raciocínio lógico. Deste modo, à leitura do filósofo alemão, a arte de Eurípedes esteve a serviço do entendimento, e não mais da relação mítica das tragédias áticas. Cito Nietzsche:

$\mathrm{Na}$ linguagem da tragédia antiga havia para ele [Eurípedes] muita coisa de ofensiva, ao menos enigmática; em especial, achava haver demasiada pompa para relações muito comuns, demasiados tropos e monstruosidades para a simplicidade dos caracteres. Assim, cismando [...] confessava a si mesmo que não entendia seus grandes predecessores [Ésquilo e Sófocles]. Mas como o entendimento significava para ele a própria raiz de todo desfrute e criação, precisava indagar e mirar à sua volta para saber se alguém mais pensava como ele e confessava igualmente aquela incomensurabilidade (NIETZSCHE, 2000, § 11).

À leitura de Danto acerca do Nascimento da Tragédia em Nietzsche, a preocupação de Eurípedes em "tornar o herói ou a heroína mais planos, mais parecidos com as pessoas comuns", a fim de que "sua conduta pudesse ser incorporada sem grandes esforços às crenças e práticas com que racionalizamos nossos comportamentos, reconhecendo-as como verossímeis em 
nossas vidas", antepôs-se à apresentação dos antigos heróis, representados de modos demasiadamente distantes às motivações incorporadas pela prática das pessoas comuns. "Por isso", diz Danto, "foram substituídos por tipos que podemos entender: donas-de-casa, maridos ciumentos, adolescentes rebeldes e assim por diante". É tal apreensão acerca da necessidade de tornar as peças trágicas inteligíveis que distanciou as peças trágicas de seus elementos ritualísticos, possibilitando, por conseguinte, o advento de um caráter extensivo ao questionamento de Eurípedes acerca do entendimento das obras: o advento do paradigma mimético como método de criação e avaliação acerca das obras 3 . Para Danto, à sentença "é mais compreensível ao entendimento a obra que melhor imita" adveio a de que "a melhor obra é a que melhor imita" e, por fim, o juízo de que a arte consiste em uma imitação de uma realidade pré-existente.

Reduzida à interpretação de que a arte consiste na imitação que reproduz uma realidade pré-existente, todavia, a arte encerra o problema de se pensar a sua própria eficiência e razão de ser. Uma primeira questão que Danto propõe é: "qual a necessidade de uma reprodução perfeita do que já temos em realidade?" (2005, p.64). Com essa interrogação, Danto não está a afirmar a irrelevância de parcela significante da história da arte, nem que tal concepção teórica não "engendra obras de arte altamente interessantes e até excepcionais" (2005, p.67). Diversamente, o que o pensador norte-americano observa é que ainda que se considere que se possa chegar ao fim almejado pelo projeto mimético, isto é, de uma imitação perfeita ao objeto real, este conduz a uma interrogação acerca do próprio projeto e se ele de fato diz respeito a uma teoria suficiente acerca do que é arte.

Intitulado por Danto “dilema de Eurípedes", tal asserção afirma que "uma vez completado o programa mimético, o 
produto fica tão parecido com o que se encontra na realidade" que, consequentemente, justo por se tornar idêntico ao real caberá perguntar "o que o torna uma obra de arte?" (2005, p.68). Prossegue Danto.

Eurípedes conseguiu estabelecer uma superfície artística inteligível nos termos das categorias da vida ordinária. A arte passa a ser então verdadeiramente uma imitação, no sentido de semelhante ao possível. Mas [...] logo nos deparamos com o problema proposto por Sócrates no Livro X de A República: que sentido tem uma arte tão parecida com a vida que se torna impossível determinar uma diferença entre a arte e a vida em termos de conteúdo interno? [...] sob a pressão da pergunta de Sócrates, a arte mimética fracassa quando tem sucesso, quando consegue ser como a vida. Isso é o que se pode chamar de dilema de Eurípedes (DANTO, 2005, p.65).

Ademais, prossegue o pensador estadunidense, se tomada apenas como mera imitação da realidade, a boa arte não haveria de se encerrar em uma atividade humana menor? Supondo-se um pintor, tal acepção da arte como mimesis não haveria de antepor a todo o esforço que a educação da atividade artística exigiu, bem como o empenho na realização da obra por parte do artista, um fim que não diferiria sua atividade à de um espelho? E, neste caso, o espelho não desqualificaria a atividade do artista, em razão de potencialmente imitar melhor e em uma quantidade maior do que o artista mimético, visto que este precisará passar por todo um processo de formação artística para dotá-lo de capacidade técnica para a representação e, ademais, 
empenhará grande esforço para a realização de uma obra, quando, diversamente, basta ao espelho ser contraposto a uma imagem para que a reproduza? Por sua vez, que valor teria neste caso a arte como realidade mimética perante a realidade existente?

Há de se notar que a crítica de Danto, aqui, não diz respeito à realização de obras que representam uma realidade pré-existente, mas, ao paradigma que propõe pensar que a arte seja imitação. Pensada sob esse prisma, o paradigma acaba por influir na própria realização das obras. Mais do que isso, para Danto fezse presente enquanto projeto histórico de parcela significante da história da arte em seu caráter extensional, de modo que tãosomente com a tomada de consciência, por parte dos artistas e do público, de que a arte residiria para além da simples imitação, que se fez propor na própria produção artística a interrogação acerca dos meios e métodos de representação (caso do Modernismo) e, por fim, a questão não mais da imitação, mas do próprio objeto transfigurado em outra identidade, agora artística (como bem exemplifica sua teoria a partir das Brillo Boxes, de Andy Warhol).

\section{NOTAS}

${ }^{1}$ Este artigo é uma versão ampliada da comunicação "O dilema da mimesis em Arthur Danto", apresentado em 11 de setembro de 2013 no I Seminário de Estética e Crítica de Arte, na Faculdade de Filosofia, Letras e Ciências Humanas da Universidade de São Paulo - FFLCH/USP. ${ }^{2}$ Professor Assistente da área de Filosofia da Universidade Estadual de Feira de Santana (UEFS). Mestre em filosofia pela Universidade Federal de Goiás (UFG). Doutorando em filosofia na Universidade Federal de 
Minas Gerais (UFMG). Contato: pablonascimento01@yahoo.com.br. ${ }^{3}$ Vale notar que semelhante constatação é estendida às outras manifestações artísticas por Arnold Hauser, em sua História social da arte e da literatura, na qual constata uma gradativa mudança formal para o caráter mimético nas esculturas dos séculos VI e V a.C., o emprego das pinturas para a confecção de retratos, e a mudança temática dos textos para uma temática biográfica. Observa, ainda, que a decadência do caráter ritualístico trágico pode ser exemplificada no fato de que durante todo o século IV a.C., em Atenas, não houve a construção de um único templo novo (Cf. HAUSER, 2000, pp.90-101). 


\section{REFERÊNCIAS}

DANTO, A. Após o fim da arte: a arte contemporânea e os limites da história. Tradução Saulo Krieger. São Paulo: EdUSP/Odysseus, 2006.

DANTO, A. O mundo da arte. Tradução de Rodrigo Duarte. Artefilosofia, Ouro Preto, n.1, p.13-25, jul. 2006.

DANTO, A. A transfiguração do lugar comum. Tradução Vera Pereira. São Paulo: Cosac Naify, 2005.

DANTO, A. The end of art: a philosophical defense. History and Theory, New York, v.37, n.4, p.127-143, Dec. 1984.

DANTO, A. The transfiguration of commonplace. The Journal of Aesthetics and Art Criticism, Philadelphia, PA, v.33, n.2, p.139148, Jun.1974.

HAUSER, Arnold. História social da arte e da literatura. Tradução CABRAL, Álvaro. São Paulo: Martins Fontes, 2000.

NIETZSCHE, F. Sócrates e a tragédia. In: A visão dionisíaca do mundo e outros textos da juventude. FERNANDES, Marcos Sinésio; SOUZA, Maria Cristina. São Paulo: Martins Fontes, 2005.

NIETZSCHE, F. O nascimento da tragédia, ou helenismo e pessimismo. Tradução GUINSBURG, J. São Paulo: Companhia das Letras, 2000. 